\title{
Research on the Listed Dairy Business Growth Based on AHP Liu Fang ${ }^{1 *}$, Li chao ${ }^{2}$, He Zhongwei ${ }^{3}$ \\ ${ }^{1}$ College of Economics and Management, Beijing University of Agriculture, Beijing 102206, P. R. China
}

Keywords: Dairy processing enterprises; Development; Analytic Hierarchy process; Assessment

\begin{abstract}
Dairy Processing Industry is the Primary component of Dairy Industry. The Development of Enterprises is significant to Investors, Consumers and Enterprises Themselves. This Article evaluates four listed companies, Sanyuan, Mengniu, Yili and Bright, and gives suggestions for further development of dairy industry according to their assessment ranking results. The growth evaluation index system is built according to the factors that have effects on the development of enterprises. Countermeasures and suggestions are given by applying Analytic Hierarchy Process (AHP) to assign an appropriate value to the weight of specific evaluation index in different finical indicator systems and comprehensively assessing the growth of the four listed dairy enterprises according to the places of synthesis score.
\end{abstract}

\section{Introduction}

Business growth reserch refers to the study of influencing factors of business growth and its interaction,and the findings are generally referred to as the enterprise growth theory. Business growth means the ability to tap the idle-resources, continouslly to achieve sustainable production of the potential value.It is an expectation of its future based on the condition and capacity of enterprise's development, which determines the possibilty and degree of its development. Reasonable assessment of the enterprise's growth and suitable business assenment method can accurately predict the company's future growth. It can not only provide the basis for decision-making of stock investors, but also be of great significance for the proposition of the long-term effective plan for enterprises.

In recent years,a lot of researches on business growth can be found.For example,in 2012, Huang Xiao conducted a factor analysis on the basis of the data on financial statements in 2010 of Chinese private real estate listed companies.He drew the conclusion that our private real estate listed companies were mainly driven by enterprise's profitability of return on assets, return on equity, earnings per share and return on total assets and that internal risk management. Li Jinzhou et al (2008), Li Xiaofei (2008), Gong Fuhe(2013) are empirically studied the growth of different listed companies by using factor analysis. Li Changchun et al (2011) and Zhang Qian (2011) established the evaluation index system of the growth of listed companies, and conducted the empirical study by making use of catastrophe progression method. Li Yijuan (2009) selected 36 financial indicators from solvency, operational capability, shareholder profitability, cash flow, profitability and developing competence of enterprises to determine the growth of the listed companies in China. Through empirical study of 24 listed companies by means of Logistics regression model, they concluded that the largest four indicators were ratio of current liabilities, retained earnings per share, tangible net debt ratio and cash flow to current liabilities ratio Cui $\mathrm{Lu}$ et al(2011) compared the measures of the growth of small and medium-sized enterprises of science and technology by applying Analytical Hierarchy - Grey Relational Comprehensive Evaluation Method. Chen Aicheng

\footnotetext{
1. Supported by Beijing Natural Science Foundation (9142004), “Beijing Innovation Team of Technology System in Dairy Industry" and Program for New Century Excellent Talents in University (NCET-10-009)

Author. Dr. Fang Liu. Economics \& Management School of BUA, No. 7 Beinong Road, Changping District, Beijing 102206, P. R. China. Tel. : 86010 80795627; fax: 86010 80799151, e-mail:1ivfang@sohu.com

*Corresponding author. Dr.Zhongwei He. Economics \&Management School of BUA, No. 7 Beinong Road, Changping District, Beijing 102206, P. R. China. Tel. : 8610 80799151; fax: 861080799151 e-mail:hzw28@126. com
} 
(2012), He Yijia (2008), Cheng Haifeng et al (2005) constructed the index system of enterprise growth evaluation, They, and assigned an appropriate value to each evaluation index weight through comprehensive evaluation of AHP and comprehensively assessed the growth of enterprises. In 2008, by combining qualitative and quantitative studies, Chen Xiaolan constructed the model of assessing the growth of small and medium-sized enterprises. Multi-indicators were taken into account through, analytic hierarchy process and by empirical research; it was proved to be a scientific and practical method.

On the basis of financial statement of dairy enterprises and through the importance of financial indicators for enterprises, this paper comprehensively assesses. The growth of the four listed dairy enterprises.

\section{Method Descriptions}

AHP is a complex system which takes multiple objective decision making problems as a whole. According to the sequence of the ultimate goal and the various sub-objectives, evaluation methods and alternative programs, the policies are divided into different hierarchical structures. The maximum weight of the element of each target to the element of upper target is obtained by the way of solving the judgment matrix eigenvectors. Finally through the calculation of weighted sums the final weights are incorporated into the weight of the general target, and the biggest one of final weights is the optimal scheme.

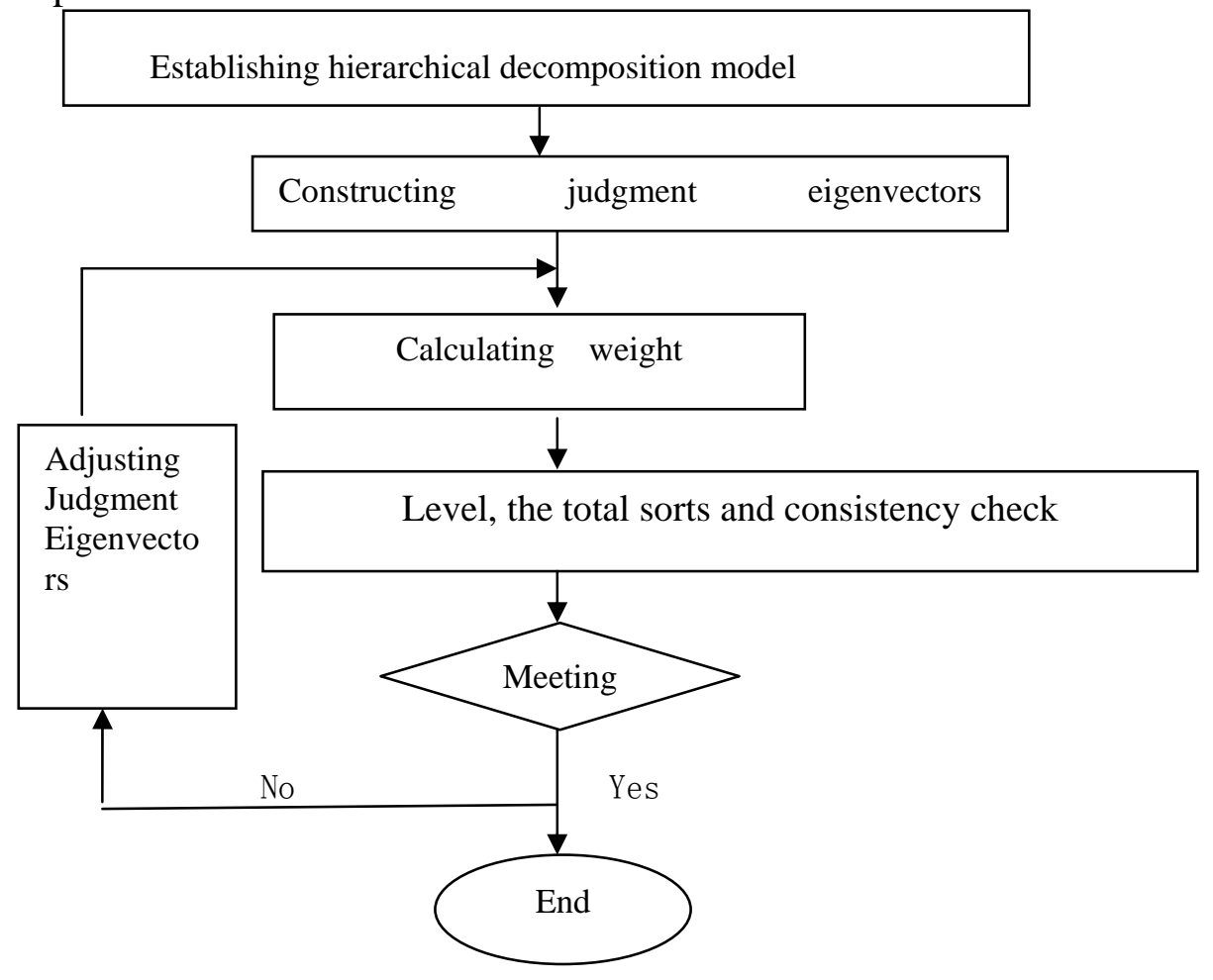

Figure 1 Use flow and steps of the AHP

\section{Growth Assessments of Beijing Dairy Enterprises}

\subsection{Growth assessment system settings and hierarchies of Beijing dairy enterprises}

To assess listed dairy company's growth through AHP, we must first determine the index system of the dairy business growth. Afterwards, the hierarchy of comprehensive assessment must be established according to the characteristics of business growth and the nature of assessment index. In order to make the results more realistic, concise and objective, 12 financial indicators of profitability, development capacity, solvency and operation capacity were chosen to assess the growth of the listed dairy enterprises according to the principle of being generally applicable and easy to collect indicators. Hierarchical model is shown in Table 1. 
Table 1 Growth assessment index system of Beijing dairy enterprises

\begin{tabular}{|c|c|c|}
\hline $\begin{array}{l}\text { Target layer } \\
\text { (A) }\end{array}$ & Indicator category (B) & Item (C) \\
\hline \multirow{12}{*}{$\begin{array}{l}\text { Dairy } \\
\text { business } \\
\text { growth }\end{array}$} & \multirow{3}{*}{ Profitability indicators(B1) } & OPE (C1) \\
\hline & & Sales profit (C2) \\
\hline & & ROE (C3) \\
\hline & \multirow{3}{*}{$\begin{array}{l}\text { Capacity } \\
\text { indicators (B2) }\end{array}$} & $\begin{array}{l}\text { Main business revenue growth } \\
\text { (C4) }\end{array}$ \\
\hline & & Total asset growth (C5) \\
\hline & & Net Profit Growth (C6) \\
\hline & \multirow{3}{*}{ Solvency indicators (B3) } & Current ratio (C7) \\
\hline & & Quick ratio (C8) \\
\hline & & The gearing ratio (C9) \\
\hline & \multirow{3}{*}{$\begin{array}{l}\text { Operation } \\
\text { indicators (B4) }\end{array}$} & Current Assets Turnover (C10) \\
\hline & & $\begin{array}{ccc}\text { Accounts } & \text { receivable } & \text { turnover } \\
\text { ratio }(\mathrm{C} 11) & & \\
\end{array}$ \\
\hline & & Total Turnover (C12) \\
\hline
\end{tabular}

\subsection{Select sample enterprises}

This paper selected four dairy enterprises, Sanyuan (600,429), Mengniu(02319), Yili(600887), and Bright (600597), as the research sample. 12 economic indicators were collected from the public financial statements of the listed companies. In order to reflect the ongoing business growth more accurately and exclude the impact of unexpected factors on calculation, the data used in this research was the weighted time-series data from 2010 to 2012.

\subsection{Processing sample index data}

In the 12 financial indicators (2010-2012) of the four listed companies, the closer the year is, the better they can show the current state of the enterprise, so the financial indicators weight of the past five years were set as follows: 0.5 for 2012, 0.3 for 2011, and 0.2 for 2010 (as it was a transitional period---the recovery time for each dairy enterprise development). Then the three weighted data, the weighted average of 12 financial indicators in three years, were calculated, and they severed as assessment criteria of the four enterprises. As shown in Table 2,

Table 2 the three-year average of the financial indicators is recorded as $X 1-X 12$.

\begin{tabular}{lllllllllllll}
\hline enterprises & $\mathbf{X}_{\mathbf{1}}$ & $\mathbf{X}_{\mathbf{2}}$ & $\mathbf{X}_{\mathbf{3}}$ & $\mathbf{X}_{\mathbf{4}}$ & $\mathbf{X}_{\mathbf{5}}$ & $\mathbf{X}_{\mathbf{6}}$ & $\mathbf{X}_{\mathbf{7}}$ & $\mathbf{X}_{\mathbf{8}}$ & $\mathbf{X}_{\mathbf{9}}$ & $\mathbf{X}_{\mathbf{1 0}}$ & $\mathbf{X}_{\mathbf{1 1}}$ & $\mathbf{X}_{\mathbf{1 2}}$ \\
\hline SANYUAN & 20.56 & 0.63 & 2.32 & 14.08 & 11.84 & -41.04 & 0.92 & 0.71 & 44.90 & 2.93 & 17.41 & 0.99 \\
MEINIU & 22.59 & 4.22 & 11.74 & 8.85 & 6.86 & 2.04 & 1.44 & 1.23 & 40.34 & 3.59 & 58.95 & 1.92 \\
YILI & 29.16 & 4.07 & 24.40 & 18.33 & 11.99 & 40.37 & 0.62 & 0.36 & 65.65 & 5.02 & 140.29 & 2.11 \\
BRIGHT & 33.98 & 2.38 & 8.46 & 19.47 & 29.33 & 32.97 & 1.16 & 0.89 & 55.78 & 3.34 & 11.50 & 1.73 \\
\hline
\end{tabular}

Source: Financial statements data

\subsection{Determinthing the structure of matrices through pairwise comparison}

According to the principles of the Analytic Hierarchy Process, the judgment matrix of each sub-goal in hierarchical model was obtained by distinguishing the comprehensive financial appraisal of each sub-goal. The purpose is to get the value of the importance of each target in the hierarchy and to quantify various qualitative factors, and thus the weights of various factors on the parent factors were indicated more objectively. Constructing pairwise comparison of results and using the scale method of 1-9 proposed by Professor T.L.Saaty, we can get five comparative judgment matrixes. One of them is the fourth-order judgment matrix of the criteria layer to the target layer which can be recorded as $A$. The other four indicator layers are 3 order matrix to criterion layers, and are respectively recorded as B 1, B 2, B 3,, B 4 . See Table 3 - Table 7.

Table 3: Judgment Matrix of Comprehensive Assessment of Enterprise Growth

$\mathrm{A}=$

\begin{tabular}{llll}
$\mathrm{B}_{1}$ & $\mathrm{~B}_{2}$ & $\mathrm{~B}_{3}$ & $\mathrm{~B}_{4}$ \\
\hline 1 & 3 & 5 & 7
\end{tabular}




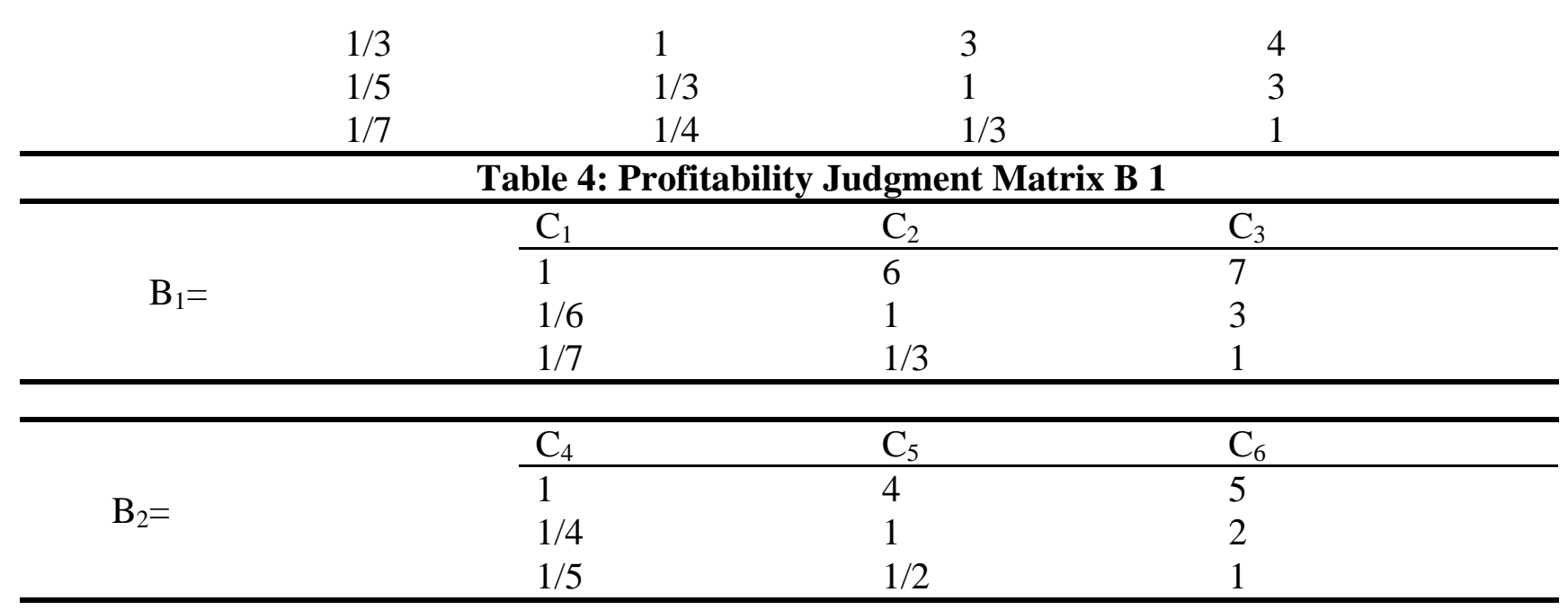

Table 5: Judgments matrix B 2 of Developing ability Table 6: Judgment Matrix B 3 of solvency

\begin{tabular}{cccc}
\hline \multirow{3}{*}{$\mathrm{B}_{3}=$} & $\mathrm{C}_{7}$ & $\mathrm{C}_{8}$ & $\mathrm{C}_{9}$ \\
\cline { 2 - 4 } & 1 & 4 & 8 \\
& $1 / 4$ & 1 & 3 \\
& $1 / 8$ & $1 / 3$ & 1 \\
\hline & Table 7: Judgment Matrix B 4 of Operation Ability \\
\hline & $\mathrm{C}_{10}$ & $\mathrm{C}_{11}$ & $\mathrm{C}_{12}$ \\
\cline { 2 - 4 } $\mathrm{B}_{4}=$ & 1 & $3 / 5$ & $8 / 5$ \\
& $5 / 3$ & 1 & 5 \\
& $5 / 8$ & $1 / 5$ & 1 \\
\hline
\end{tabular}

\subsection{Single hierarchical ranking and consistency test}

To normalize the eigenvector of Maximum Eigenvalue of judgment matrix is to make sure that the sum of elements of the vector is equal to 1. The normalized Element is the rank weight for the relative importance of a factor in the same hierarchical factors to the upper ones. This process is called a single hierarchical ranking. The criterion for measuring whether the judgments matrix is appropriate or not is whether the consistency of judgmentS in a matrix. To Confirm whether the results obtained from the single hierarchical ranking and AHP is reasonable, consistency test is needed. Consistency check is to determine the limit of inconsistency of the matrix.

According to the calculation, the maximum eigenvalues of the judgments matrix $A$ is $\max =4.0007$; the normalized feature vector $\mathrm{WK}=(0.5634,0.2513,0.1248,0.0605) \mathrm{T}$; consistency index C I $=-n / n-1=4.0007-4 / 4-1=0.0002 ; n=4$ in the numerical table of random check of consistency index was $\mathrm{R} \mathrm{l}=0.9$, so consistency ratio $\mathrm{CR}=\mathrm{C} \mathrm{I} / \mathrm{R} \mathrm{I}=0.0002 / 0.9$. The calculation shows that $\mathrm{C} \mathrm{R}=0.0003<0.1$. So A passed consistency test.

According to the above calculation principle, weight vectors of single hierarchical ranking for judgment matrix B 1, B 2, B 3, B 4 were respectively worked out and consistency is tested. The results are shown in Table 8.

Table 8: Feature vector and consistency index for every matrix

\begin{tabular}{rcccc}
\hline $\boldsymbol{K}$ & $\mathbf{1}$ & $\mathbf{2}$ & $\mathbf{3}$ & $\mathbf{4}$ \\
\hline $\boldsymbol{W}_{\boldsymbol{K} \mathbf{1}}$ & 0.739 & 0.681 & 0.715 & 0.283 \\
$\boldsymbol{W}_{\boldsymbol{K} 2}$ & 0.179 & 0.201 & 0.206 & 0.573 \\
$\boldsymbol{W}_{\boldsymbol{K} 3}$ & 0.082 & 0.118 & 0.079 & 0.144 \\
$\mathbf{K}$ & 3.000 & 3.000 & 3.000 & 3.014 \\
$\boldsymbol{C \boldsymbol { I } _ { \boldsymbol { K } }}$ & 0.000 & 0.000 & 0.000 & 0.007 \\
$\boldsymbol{R I}_{\boldsymbol{K}}$ & 0.580 & 0.580 & 0.580 & 0.580 \\
$\boldsymbol{C R}_{\boldsymbol{K}}$ & 0.000 & 0.000 & 0.000 & 0.012 \\
\hline
\end{tabular}

The above calculation shows that CR K $(\mathrm{k}=1,2,3,4)$ is less than 0.1 , therefore, the matrix B 1, B 2, B 3, B 4 have passed the consistency test. 


\subsection{The general hierarchical ranking and consistency test}

\section{1) The general hierarchical ranking}

The general hierarchical ranking is to work out the weights of the importance of all factors in the hierarchy with regard to the upper one by making use of the single ranking results of all hierarchies in the same hierarchy. It needs to be conducted from one hierarchy to another hierarchy and from top to bottom. For the second one below the highest hierarchy, the single hierarchical ranking is the general one. Taking the generalized eigenvector corresponding to the maximum positive characteristic root of comparative judgement matrix of the criteria layer and the overall target layer as the weight vector, adding weight to the eigenvector corresponding to the maximum positive characteristic root of the index layer and the criterion layer, we can arrive at the synthetic weight of each assessment index as shown in Table 9:

Table 9: Synthetic weight of each index number

\begin{tabular}{|c|c|}
\hline Assessment indexes & Synthetic weight of assessment indexes \\
\hline $\mathrm{X}_{1}(\mathrm{OPE})$ & $Z_{11}=a_{1} w_{11}=0.5634 * 0.7394=0.4166$ \\
\hline $\mathrm{X}_{2}$ (return on sales) & $Z_{12}=a_{1} w_{12}=0.5634 * 0.1788=0.1007$ \\
\hline $\mathrm{X}_{3}(\mathrm{ROE})$ & $Z_{13}=a_{1} w_{13}=0.5634 * 0.0818=0.0461$ \\
\hline $\mathrm{X}_{4}$ (main business revenue growth) & $Z_{21}=a_{2} w_{21}=0.2513 * 0.6806=0.1710$ \\
\hline $\mathrm{X}_{5}$ (total asset growth) & $Z_{22}=a_{2} w_{22}=0.2513 * 0.2014=0.0506$ \\
\hline $\mathrm{X}_{6}$ (net profit growth rate) & $Z_{23}=a_{2} \boldsymbol{w}_{23}=0.2513 * 0.1179=0.0296$ \\
\hline $\mathrm{X}_{7}$ (current ratio) & $Z_{31}=a_{3} w_{31}=0.1248 * 0.7146=0.0892$ \\
\hline $\mathrm{X}_{8}$ (Quick Ratio) & $Z_{32}=a_{3} w_{32}=0.1248 * 0.2064=0.0258$ \\
\hline $\mathrm{X}_{9}$ (asset-liability ratio) & $Z_{33}=a_{3} w_{33}=0.1248 * 0.0789=0.0098$ \\
\hline $\mathrm{X}_{10}$ (current asset turnover) & $Z_{41}=a_{4} w_{41}=0.0605 * 0.2826=0.0171$ \\
\hline $\mathrm{X}_{11}$ (accounts receivable turnover ratio) & $Z_{42}=a_{4} w_{42}=0.0605 * 0.5733=0.0347$ \\
\hline $\mathrm{X}_{12}$ (total asset turnover) & $Z_{43}=a_{4} w_{43}=0.0605 * 0.1442=0.0087$ \\
\hline
\end{tabular}

The weight vector of the general hierarchical ranking can therefore be gained and be denoted by Z (0.4166, 0.1007, 0.0461, 0.1710, 0.0506, 0.0296, 0.0892, 0.0258, 0.0098, 0.0171, 0.0347, $0.0087) \mathrm{T}$

\section{2 ) Consistency test}

The concordance index CIK and random index RI K of criterion layer B 1, B 2, B 3, B 4 to target layer $\mathrm{A}$ can be seen from table 9 . And $\mathrm{CR}=(0.5634 * 0.02 * 0.0017+0.1248+0.2513$ $+0.0605 * 0.0069 * 0.0001) / 0.58 *(0.5634+0.2513+0.1248+0.0605)=0.0010<0.1$. So the general hierarchical ranking passed the consistency test.

\subsection{Analysis of evaluation results}

\section{1) Assessment of Comprehensive Index}

As can be seen from Table 10, the profitability index, accounting for $56.34 \%$ of the total weight, ranked first. As we all know, the profitability index is the most effective and influential index for measuring development capacity of the enterprise. The development ability showed the second high percentage --- 25.13\%. Though the solvency and operating capacity have lower ranking and are less important than the first two indexes, they cannot be ignored either.

Table 10: Comprehensive weight of the four dairy enterprises

\begin{tabular}{|c|c|c|c|c|c|}
\hline First grade & Weight & $\begin{array}{l}\text { Importance } \\
\text { ranking }\end{array}$ & $\begin{array}{l}\text { Second grade } \\
\text { indexes }\end{array}$ & weight & Comprehensive weight \\
\hline \multirow{4}{*}{$\mathrm{B}_{1}$} & \multirow{3}{*}{0.5634} & \multirow{3}{*}{1} & $\mathrm{C}_{1}$ & 0.7394 & 0.4166 \\
\hline & & & $\mathrm{C}_{2}$ & 0.1788 & 0.1007 \\
\hline & & & $\mathrm{C}_{3}$ & 0.0818 & 0.0461 \\
\hline & \multirow{3}{*}{0.2513} & \multirow{3}{*}{2} & $\mathrm{C}_{4}$ & 0.6806 & 0.1710 \\
\hline \multirow{2}{*}{$\mathrm{B}_{2}$} & & & $\mathrm{C}_{5}$ & 0.2014 & 0.0506 \\
\hline & & & $\mathrm{C}_{6}$ & 0.1179 & 0.0296 \\
\hline \multirow{2}{*}{$\mathrm{B}_{3}$} & \multirow{2}{*}{0.1248} & \multirow{2}{*}{3} & $\mathrm{C}_{7}$ & 0.7146 & 0.0892 \\
\hline & & & $\mathrm{C}_{8}$ & 0.2064 & 0.0258 \\
\hline
\end{tabular}




\begin{tabular}{|c|c|c|c|c|c|}
\hline \multirow{4}{*}{$\mathrm{B}_{4}$} & \multirow{4}{*}{0.0605} & \multirow{4}{*}{4} & $\mathrm{C}_{9}$ & 0.0789 & 0.0098 \\
\hline & & & $\mathrm{C}_{10}$ & 0.2826 & 0.0171 \\
\hline & & & $\mathrm{C}_{11}$ & 0.5733 & 0.0347 \\
\hline & & & $\mathrm{C}_{12}$ & 0.1442 & 0.0087 \\
\hline
\end{tabular}

\section{2) Assessment of criterion layers}

Standardizing the financial index data of four dairy enterprises helps to work out the scores and rankings for every indexes of criterion layers, as shown in Table 11.

Comprehensive assessment results of four listed dairy enterprises can be reached by multiplying the synthetic weights of indexes by three-year weighted average of indexes, as listed in Table 12. Erie shares came top overall. It can be seen that the company's business growth index is the highest. That is to say, the higher the company's growth index is, the better the growth of the business becomes. Among the four enterprises, the growth indexes of Yili and Bright are relatively higher, followed by Mengniu Dairy, and Sanyuan came right at the bottom of the list. From the comprehensive weight of the four dairy enterprises in Table 10 we can see that the higher the index data of main operating margins is, the higher the comprehensive ranking will be. The main reason is that the total weight of main operating margins is the biggest, and it reflects the enterprise's growth to a great extent.

Among the four listed dairy enterprises, Erie shares owns the best growth conditions. Both its solvency and operational capabilities rank first; profitability and development capacity rank second; the ranking of all capacity indexes has much superiority than the other three. The financial index in profitability and development capacity of Bright Dairy ranked first and solvency also has certain advantages, but the poor performance of its operating capacity led to its dramatic decline in all-round strength and unfortunately came second. Therefore, in order to improve its development capacity and better its growth, it's necessary for Bright Dairy to improve its operational capabilities. Mengniu Dairy is in the third place. Its operating capacity is relatively good, but its overall strength in profitability, capacity development and solvency is not very strong and therefore should be strengthened. At the bottom of the list is Sanyuan shares. Its profitability, development capacity and solvency are the lowest.

Table 11: Scores and rankings in evaluation index of four dairy enterprises

\begin{tabular}{|c|c|c|c|c|c|}
\hline Evaluation index & & Sanyuan & Mengniu & Yili & Bright \\
\hline \multirow{2}{*}{ Profitability } & Scores & 8.5708 & 10.3763 & 13.6827 & 14.7835 \\
\hline & Rank & 4 & 3 & 2 & 1 \\
\hline \multirow{2}{*}{ Development capacity } & Scores & 1.7921 & 1.9218 & 4.9377 & 5.7922 \\
\hline & Rank & 4 & 3 & 2 & 1 \\
\hline \multirow{2}{*}{ Solvency } & Scores & 0.5426 & 0.5574 & 0.7113 & 0.6759 \\
\hline & Rank & 4 & 3 & 1 & 2 \\
\hline \multirow{2}{*}{ Operational capacity } & Scores & 0.6625 & 2.1228 & 4.9702 & 0.4712 \\
\hline & Rank & 3 & 2 & 1 & 4 \\
\hline
\end{tabular}

Table 12: Drowth ranking of four dairy enterprises

\begin{tabular}{lll}
\hline Short form & Business Growth Index & Comprehensive ranking \\
\hline Sanyuan shares & 11.7312 & 4 \\
Mengniu Dairy & 14.9783 & 3 \\
Erie shares & 24.3019 & 1 \\
Bright Dairy & 21.7229 & 2 \\
\hline
\end{tabular}

\section{Analysis of growth factors of Beijing listed dairy companies}

\subsection{Technical factors}

At present, in China, both the machinery complete sets for dairy products and automatic production lines are inadequate and the production efficiency is low. So machinery in dairy enterprises is backward compared to foreign ones. The four dairy companies mainly produce liquid milk. Their cheese technology is not very mature yet. The poor equipment and outdated technology 
resulted in fewer deep processing and high value-added dairy products, which hindered the fast and healthy development of the enterprises. Subjected to capital, technology, scale and talents, the product research and development capability is not strong. Absence of high value-added dairy products and high homogeneity resulted in their lack of market segmentation and competitiveness.

\subsection{Management factors}

\section{2 .1 Finance}

Main operating margins and sales margins have a positive correlation with the growth of the corporation. The above analysis indicates that in 2012, operating results of Sanyuan, Mengniu, Yili and Bright have been improved to some extent, but the growth is slow. This is because in recent years, with the rise in the cost of raw milk, the cost of feed and forage and labor costs continue to rise, thus the company's production costs increased. Therefore, the dairy industry should strive to control production costs and reduce production costs. Bright's development capacity is at its best, and Sanyuan's is relatively poor, being mainly affected by the melamine scandal. Bright owns the highest total assets growth rate, which indicates that its rapid expansion of assets. Solvency of enterprises can further reflect their strength of sustained business capability, which is one of the major concerns for managers. Overall, the operating capacity of Yili is the strongest, while Sanyuan, Mengniu and Bright should improve operational capability by strengthening the management of their funds and assets. Total asset turnover of four dairy companies are not very high, which shows that their sales ability is not great, yet competitiveness of products has a lot to do with it.

\section{2 .2 Milk Sources}

At present, the four dairy enterprises in Beijing have built specialized milk source bases such as Lvhe Breeding Center of Sanyan. As these larger breeding centers cannot satisfy dairy processing companies' need for milk sources, a small part of milk sources comes from dairy-breeding plot and free-range farming, thus, the stability of them is not satisfactory. With the decrease of profits of ranches, the number of farms has dropped, and milk sources will be fewer and fewer. In short, the development of milk sources falls behind the development of market of dariy enterprises. On the other hand, a few dairy farmers adulterated and watered the raw milk for the pursuit of profit. However, the dariy enterprises only quickly sampled the raw milk sent along. So this directly afftected the quality of the products of dairy enterprises, and severely restricted their healthy development. In additon, most of the national quality and health standards were formulated more than a decade ago, and some of which are outdated. What's more, belonging to different departments, having less indexes and backward inspection method, the supervision of the whole process of producing and processing cannot be achieved and the insufficient supervison had led to the variable quality of dairy products.

\subsection{Policy}

In recent years, as the government has provided more support for the dairy business and strengthen policy support for the development of the dairy industry, dairy industry has maitained a rapid and sound development. However, being of no positive guidance and supervision of the government, a few companies tooke an extensive mode of operation in order to seek lower production costs. Hence "Sanlu milk powder incident" in 2008 occurred and a series of adulteration of dairy enterprises arouse afterwards. Consumers's confidence in domestic milk brands has therefore been badly dented ans some consumers even don't trust domestic milk brands any more and rush to purchase some imported milk powder. Due to the melamine scandal, Bright Dairy lost 280 million yuan, and Mengniu suffered the greatest loss of 948.6 million yuan. Although Sanyuan, Mengniu, Yili and Bright are domestic leading enterprises, their development, product structure, technology, etc. still fall far behind other foreign companies. Furthermore, the government's support in finance, taxation, credit, etc. is inadequate. Consequently, it's extremely difficult for enterprises to expand and introduce advanced technology for lack of money.

\section{Suggestions}

Based on the above research results, we believe that the promotion of the growth of Beijing dairy 
business should be conducted from the following aspects:

\subsection{Increase high-tech investment}

Now that dairy enterprises are on a small-scale, production scale must be expanded and production cost decreased in order to increase business growth. Meanwhile, advanced equipment has to be brought in to improve productivity and new product lines be added. Liquid milk production should be vigorously developed; the shelf life should be prolonged and nutritional level should be imporved. Other measures should also be taken: advocating the production of natural dairy products; strengthening green dairy research; researching and developing the new dairy products integrated with health care, nutrition, medical care features; increasing the added value on dairy products. At the same time, develop their own new products by the way of vigorously introducing advanced foreign technologies. Finally, develop high value-added products with functional and regional specialties to enrich variety of products, increase subdivisions of product variety, and expand consumer groups.

\subsection{Strengthen supervision of milk sources}

Currently, the quantity and quality of local raw milk in Beijing can not meet the needs of the dairy processing enterprises and milk sources are in short supply. As a result, a suitable place for cows to grow should be found in Beijing. It's necessary to establish specialized cooperative organizations of cow raising, to centralize the numerious fragmented dairy farmers to the dairy-breeding plot, to unify cows' epedemic prevention, to provide unified feed formula and to unify milking and sales to supply fresh milk to the local dairy processing enterprises. In this way, not only the interests of dairy farmers can be ensured and the risk of operation can be reduced, but also the quantity and quality of milk sources can be effectively controlled so that the quality of products in local dairy processing enterprises can be guaranteed.

\subsection{Enhance the government's support}

The development of the dairy processing enterprises also needs active guidance of the government and extensive participation of enterprises. First, the government should offer infrastructure to the dairy processing companies, so as to reduce business costs, increase market competitiveness of products, and accelerate business growth. For enterprises, they should increase the investment of refrigeration, preservation, transportation, packaging and other infrastructure to avoid similar incidents as melamine, and to enable them to develop in a more healthy and orderly way.

\section{References}

[1] Chen Xiaolan, Liu Jinanbing, Bi Xiaoxia. Growth evaluation research of SMEs in Shandong province based on AHP [J]. Shandong Finance Journal, 2008 (4)

[2] Cheng Haifeng, Lv Daoming. Enterprise Growth evaluation model based on hierarchy analysis [J]. New Theoretical Exploration, 2005 (9)

[3] Cui Lu,Zhong Shuhua Growth measure of high-tech SME Based on AHP - gray correlation comprehensive evaluation [J]. Science \& Technology Progress and Policy, 2011 (12)

[4] He Yijia. Application of AHP in Comprehensive Evaluation of enterprise growth [J]. Business and management, 2008 (3)

[5] Chen Aicheng. Application of AHP in SME growth analysis [J]. Economics and Managements space, 2012 (1)

[6] Bao Limin. Consolidated financial analysis based on AHP[J]. Business Accounting, 2012 (8) 